\title{
Front-Face Fluorescence Measurement of Photosensitizers and Lipid Oxidation Products During the Photooxidation of Butter
}

\author{
A. Veberg, ${ }^{*} \dagger^{1}$ E. Olsen, ${ }^{*} \dagger$ A. N. Nilsen, ${ }^{*}$ and J. P. Wold ${ }^{*}$ \\ *Matforsk AS, Norwegian Food Research Institute, Osloveien 1, NO-1430 Ås, Norway \\ †Norwegian University of Life Sciences, Department of Chemistry, Biotechnology, and Food Science, PO Box 5003, NO-1432 Ås, Norway
}

\begin{abstract}
This paper shows that fluorescence spectroscopy can measure both degradation of photosensitizers and formation of lipid oxidation products in light-exposed butter. The photosensitizers were already notably degraded after $4 \mathrm{~h}$ of light exposure, whereas fluorescent lipid oxidation products were detected after $5 \mathrm{~d}$. The fluorescence measurements were highly correlated with sensory assessments of acidic and rancid flavor. Photosensitizer degradation is therefore a promising indirect indicator of the onset of lipid oxidation in butter. Sensory analysis and measurement of peroxide value showed that the level of lipid oxidation was significantly higher for butter stored in air compared with butter stored in nitrogen $\left(\mathrm{N}_{2}\right)$. This might be explained by the formation of singlet oxygen from direct photooxidation and type II photosensitized oxidation. Addition of the singlet oxygen quencher $\beta$-carotene reduced the rancid flavor intensity in the air and $\mathrm{N}_{2}$ packages from 9.0 to 4.9 and from 6.5 to 4.7 , respectively. Results indicate that lipid oxidation in the butter stored in $\mathrm{N}_{2}$ was mainly caused by type I photosensitized reactions, because addition of $\beta$-carotene had little effect on the rancid flavor intensity.
\end{abstract}

Key words: fluorescence spectroscopy, photooxidation, butter, photosensitizer

\section{INTRODUCTION}

In general, dairy products are susceptible to light and are exposed to light during processing and in grocery stores. Butter is particularly susceptible to photooxidation because of its high content of fatty acids, including some unsaturated ones (Bosset et al., 1995). Light induces the degradation of proteins, lipids, and vitamins, as well as the formation of off-flavors and changes in color. The most practical way to protect dairy products

Received June 29, 2006.

Accepted December 24, 2006.

${ }^{1}$ Corresponding author: annette.veberg@matforsk.no against such degradation is to exclude all kinds of light exposure.

Photooxidation can proceed either through direct photooxidation or by a photosensitizer. Direct photooxidation is due to free radicals produced by UV light and proceeds by normal free radical chain reactions (Frankel, 2005). Oxygen can also become activated in the presence of metals or metal complexes and initiate lipid oxidation by the formation of either free radicals or singlet oxygen $\left({ }^{1} \mathbf{O}_{2}\right)$. Singlet oxygen is a very efficient oxidizing agent (Frankel, 2005).

Photooxidation by a photosensitizer can proceed through type I or type II reactions. These reactions often occur at the same time in a competitive manner. Type I reactions proceed through a free radical mechanism, and the reactions are most efficient at low oxygen concentrations (He et al., 1998). In type II reactions, the sensitizer reacts with oxygen to form ${ }^{1} \mathrm{O}_{2}$. These reactions are simpler and basically yield hydroperoxides (Spikes, 1989). Chain-breaking antioxidants will not inhibit these 2 types of photosensitized reactions. In contrast to type I reactions, type II reactions are affected by ${ }^{1} \mathrm{O}_{2}$ quenchers (Stratton and Liebler, 1997).

There are several methods to detect the photooxidation of dairy products, such as peroxide value $(\mathbf{P V})$, sensory analysis, gas chromatography, and fluorescence spectroscopy. The first 3 methods either involve the use of relatively large amounts of solvents and are time-consuming, or they are expensive. Front-face fluorescence spectroscopy, on the other hand, is a rapid and nondestructive method that has been shown to provide strong correlations with sensory analysis for photooxidation in cheese (Wold et al., 2005) and sour cream (Wold et al., 2002a).

Fluorescence evaluation of the degree of photooxidation in dairy products has been done by measuring photosensitizer breakdown (Wold et al., 2005). This serves as an indirect measurement of the actual initiation of the oxidation process and can therefore indicate the onset of early lipid oxidation. In comparison, when evaluating autoxidation in meat by fluorescence, the formation of stable fluorescent lipid oxidation products is 
measured. These are mainly tertiary oxidation products and indicate somewhat more progressed oxidation. Previous studies have shown that the fluorescent lipid oxidation products in turkey and fish give an emission peak in the 470-nm region that increases with the degree of oxidation (Veberg et al., 2006a,b). This peak can be formed by the reaction of aldehydes with proteins or AA (Yamaki et al., 1992; Veberg et al., 2006b).

Recently, Wold et al. (2005) showed that naturally occurring porphyrins and chlorophylls play an important role as photosensitizers in dairy products. The degradation of these compounds showed higher correlation with sensory-measured lipid oxidation than did the degradation of riboflavin. Hansen and Skibsted (2000) stated that riboflavin had no effect on photooxidation in a dairy spread model system that was photodegraded. The ${ }^{1} \mathrm{O}_{2}$ quencher $\beta$-carotene protected riboflavin against photooxidation and the lipids against peroxidation.

Fluorescence spectroscopy has the interesting property of being able to measure both initiation of photooxidation and formation of tertiary oxidation products. Therefore, the aim of this study was to evaluate the photooxidation of butter using this method. To better understand the phenomena measured by fluorescence, the spectra were quantitatively compared with data from other analytical methods used for lipid oxidation: sensory analysis, headspace/GC-MS, and PV. We also wanted to investigate whether packaging in nitrogen $\left(\mathrm{N}_{2}\right)$ and air would have an effect on the photooxidation processes, and how the ${ }^{1} \mathrm{O}_{2}$ quencher $\beta$-carotene would influence these reactions.

\section{MATERIALS AND METHODS}

Dairy butter (TineSmør, ekte meierismør, 500-g packages) were obtained from Tine BA (Oslo, Norway), and all packages were from the same batch. Slices of butter $(6.5 \times 6.5 \mathrm{~cm})$ with a thickness of $1 \mathrm{~cm}$ were wrapped in plastic film (Clingfilm, Toro, Norway), placed in amorphous polyethylene terephthalate-polyethylene trays (EKA AS, Hamar, Norway), and sealed with a laminate film based on oriented polyester, Biaxer 65 XX HFP AF (Wihuri Oy Wipak, Nastola, Finland; $\mathrm{O}_{2}$ transmission rate of $5 \mathrm{~cm}^{3} / 24 \mathrm{~h}$ at $23^{\circ} \mathrm{C}, 50 \%$ relative humidity) with a 511VG tray-sealing machine (Polimoon, Kristiansand, Norway). The gas in the packages was $\mathrm{N}_{2}$ with traces of $\mathrm{O}_{2}(0.03 \% \pm 0.03)$. At the start of light exposure, small holes were made in the film of half the packages so that air could penetrate. Because effective wavelengths for the photooxidation of butter are in the near-UV and blue regions (Bosset et al., 1994), the packages were covered with a violet film (357 Royal Lavendel, Rosco Laboratories Inc., Stamford, CT) that transmits light mainly between 290 and $540 \mathrm{~nm}$ (maximum at $450 \mathrm{~nm}$ ) and over $650 \mathrm{~nm}$. Between 540 and $650 \mathrm{~nm}$, less than $10 \%$ of the light is transmitted. The samples were stored for $0,4,8,12,24,36,48$ (2 d), $72(3 \mathrm{~d}), 120(5 \mathrm{~d}), 168(7 \mathrm{~d})$, and $336 \mathrm{~h}(14 \mathrm{~d})$ in an air or $\mathrm{N}_{2}$ atmosphere under 2 broadband $575-\mathrm{W}$ metal halide lamps (Osram HMI 575 W/SE, Osram, Munich, Germany), which have a relatively flat emission spectrum in the visible and near-UV region. The butter was exposed to a light intensity of $420 \pm 20$ lux, corresponding to $1.5 \pm 0.1 \mathrm{~W} / \mathrm{m}^{2}$. This level is approximately the same as the amount of light dairy products are exposed to in grocery stores. The light intensity was measured by a lux meter (Lu-Ex02 digital lux meter, Ecom Rolf Nied GmbH, Assamstadt, Germany) and by a calibrated spectrometer (Apogee Spectroradiometer, Apogee Instruments Inc., Logan, UT), which was integrated in the 280 to $800 \mathrm{~nm}$ region. Because the intensity rates as well as the spectra of such lamps are dependent on the environmental temperature, intensity measurements were carried out in the refrigerated room where the storage experiment was performed. The 2 light sources were mounted on tripods approximately $2 \mathrm{~m}$ above the floor. The packages with butter were placed on the floor, where the temperature was 3 to $4^{\circ} \mathrm{C}$. Sensory evaluation and fluorescence measurements were performed immediately after light exposure. The butter exposed for $14 \mathrm{~d}$ was evaluated only by fluorescence. Samples for PV, thiobarbituric acid-reactive substances (TBARS), and dynamic headspace/GC-MS analyses were packed in aluminum foil, vacuum-packed in plastic bags immediately after exposure, and stored at $-80^{\circ} \mathrm{C}$. Before analysis, the samples were tempered at room temperature for approximately $2 \mathrm{~h}$, transferred to centrifuge tubes, and immersed in a water bath at $70^{\circ} \mathrm{C}$ until just melted. The butter was centrifuged for 5 min at $500 \times g$ at $20^{\circ} \mathrm{C}$, and the upper lipid phase was immediately used for the PV and dynamic headspace/GC-MS analyses. The butter was stored a second time at $-80^{\circ} \mathrm{C}$ before TBARS analysis.

To investigate the effect of adding a ${ }^{1} \mathrm{O}_{2}$ quencher, dairy butter from a different batch (Tine BA) was melted in a water bath at $40^{\circ} \mathrm{C}$ and $600 \mathrm{mg}$ of $\beta$-carotene/kg (Sigma-Aldrich Chemie $\mathrm{GmbH}$, Steinheim, Germany) was added. The butter was stored in aluminum trays in a refrigerator at $4^{\circ} \mathrm{C}$ overnight. Slices of butter with a thickness of $1 \mathrm{~cm}$ were packed in $\mathrm{N}_{2}$ or air, as described above, and exposed to light for 0,3 , or $7 \mathrm{~d}$. Control samples (butter without $\beta$-carotene) stored in air and $\mathrm{N}_{2}$ were also exposed to light for $7 \mathrm{~d}$. All the samples were evaluated by sensory analysis and fluorescence spectroscopy separately from the main experiment. 


\section{Front-Face Fluorescence Measurements}

Fluorescence emission spectra were measured directly on the butter samples. The samples were placed into sample cuvettes, which exposed a flat circular surface with a diameter of $5 \mathrm{~cm}$ for the measurements. The fluorescence emission spectra in the range of 410 to $750 \mathrm{~nm}$ were measured with an excitation wavelength at $382 \mathrm{~nm}$ using an optical bench system suitable for solutions and solid samples. This excitation wavelength has earlier been shown to give good results on lipid oxidation in dairy products (Wold et al., 2002a, 2005). The excitation light was generated by a $300-$ W Xenon light source (Oriel 6258, Oriel Corporation, Stratford, CT) and passed through a 10-nm bandwidth interference filter (Oriel 59920). The light was directed onto the samples at an angle of approximately $45^{\circ}$. The spectra were collected by an imaging spectrograph (Acton SP-150, Acton Research Corporation, Acton, MA) connected to a sensitive charge-coupled device (CCDcamera, Roper Scientific NTE/CCD-1340/400-EMB, Roper Scientific, Trenton, NJ). A cutoff filter at $400 \mathrm{~nm}$ (Melles Griot 03FCG049) was positioned in front of the spectrograph slit to suppress the excitation light reflected from the sample. Exposure time was $2 \mathrm{~s}$ for normal butter and $6 \mathrm{~s}$ for butter with added $\beta$-carotene. All the samples were measured twice, and an average was used in the analysis. The field of illumination was not perfectly homogeneous, so the samples were rotated $90^{\circ}$ between each measurement to even out sample heterogeneity. To ensure stable illumination, the emission intensity at $440 \mathrm{~nm}$ at an excitation wavelength of 382 $\mathrm{nm}$ was measured from a stable fluorescence standard of washable plastic (Ciba, Basel, Switzerland) before and after the measurements. The spectra were not subjected to any kind of preprocessing before analysis.

\section{Sensory Evaluation}

The butter samples were evaluated by a trained sensory panel at Matforsk AS using descriptive sensory profiling according to the generic descriptive analysis described in Lawless and Heymann (1998). The sensory panel was made up of 9 assessors who were selected, trained, and monitored following guidelines of ISO standard 8586 (ISO, 1993), and the analyses took place in a purpose-built sensory laboratory. Prior to the analysis, the panel was trained in the definition and intensity of each of the attributes using butter with varying sensory properties (a sample stored in the dark and a sample that was light-exposed for $7 \mathrm{~d}$ ). Each assessor was served each sample $\left(2 \times 3 \mathrm{~cm}^{2}\right.$ with a thickness of $1 \mathrm{~cm}$ ) on a paper plate. The temperature of the samples was approximately $17^{\circ} \mathrm{C}$. The samples were served twice and the serving order was randomized. Water and crackers were served for cleansing the palate between samples. Intensity of the odor and flavor was evaluated, and a 9-point hedonic scale was used for evaluation of sensory attributes, ranging from the lowest (value 1.0) to the highest intensity (value 9.0) for each attribute. Each assessor evaluated the samples at individual speed on a computer system for direct recording of the data (Compusense five, v. 4.6, Compusense Inc., Guelph, Ontario, Canada). The sensory intensities for each sample of butter were obtained by averaging the individual intensities for the 9 subsamples. In the main experiment, 40 samples were evaluated, so the measurements had to be carried out over $2 \mathrm{~d}$. In the experiment with butter with added $\beta$-carotene, the evaluation was performed under red light so the color would not influence the assessment.

Acidic, sunlight, and rancid odor and flavor were evaluated. Acidic odor and flavor refer to fresh acidulous or sweet fruity. Empirically, a high intensity of these attributes indicates fresh samples. Sunlight odor and flavor are related to oxidized proteins and are the characteristic attributes in milk that has been exposed to sunlight. Rancid odor and flavor included all odors and flavors of rancidity (grass, hay, stearin, and paint).

\section{Dynamic Headspace/GC-MS Analysis of Volatile Compounds}

Volatile compounds were analyzed with a slightly modified version of a dynamic headspace/GC-MS method published by Olsen et al. (2005). Five grams of butter and $0.15 \mathrm{~g}$ of a $63.6 \mu \mathrm{g} / \mathrm{g}$ internal standard solution of heptanoic acid ethyl ester (>99\%, Sigma-Aldrich Chemie GmbH, Steinheim, Germany) in soybean oil (Mills DA, Oslo, Norway) were accurately weighed into reagent tubes $(50 \mathrm{~mL})$ with glass stoppers. The soybean oil used for the internal standard solution contained only negligible traces of volatile oxidation products prior to use. The samples were heated to $70^{\circ} \mathrm{C}$ in a water bath for 2 min and subsequently purged with $100 \mathrm{~mL} / \mathrm{min}$ of $\mathrm{N}_{2}$ through a Drechsel head for $30 \mathrm{~min}$. Volatiles were adsorbed on Tenax GR $(1 \mathrm{~mL}$ per tube, mesh size 60/80, Alltech Associates Inc., Deerfield, IL). Because the butter was separated by centrifugation prior to analysis, the lipid phase used for the analyses contained very little water. However, any traces of water were removed from the tubes by $\mathrm{N}_{2}$ flushing ( 100 $\mathrm{mL} / \mathrm{min}$ ) for $5 \mathrm{~min}$ in the opposite direction of sampling. Trapped compounds were desorbed at $250^{\circ} \mathrm{C}$ for $5 \mathrm{~min}$ in a PerkinElmer ATD400 automatic thermal desorption system (PerkinElmer, Beaconsfield, UK) and transferred to an Agilent 6890 gas chromatography system (Agilent Technologies, Palo Alto, CA) with an Agilent 5973 mass selective detector (a quadrupole) op- 
erated in electron impact mode at $70 \mathrm{eV}$. The compounds were separated on a DB-WAXetr column (etr = extended temperature range; $0.25 \mathrm{~mm}$ i.d., $0.5 \mu \mathrm{m}$ film, 30 m, J\&W Scientific, Agilent). Helium (99.9999\%) was used as the carrier gas. The temperature program began at $30^{\circ} \mathrm{C}$ for $10 \mathrm{~min}$ and increased by $1^{\circ} \mathrm{C} / \mathrm{min}$ to $40^{\circ} \mathrm{C}$, by $3^{\circ} \mathrm{C} / \mathrm{min}$ to $70^{\circ} \mathrm{C}$, and by $6.5^{\circ} \mathrm{C} / \mathrm{min}$ to $230^{\circ} \mathrm{C}$, with a final hold time of $5 \mathrm{~min}$. Integration of peaks and tentative identification of compounds were performed with HP Chemstation (G1701CA v. C.00.00, Agilent), the Wiley 130K mass spectral database (HP 61030A MS Chemstation, John Wiley \& Sons, Inc., Agilent Technologies), and the NIST98 mass spectral library (v. 1.6d, US Secretary of Commerce, Agilent). Identities of several of the components were confirmed by comparison of retention times and mass spectra of the sample peaks with those of pure standards. Concentrations of the individual volatiles were calculated as nanograms per gram of butter lipids based on the internal standard. No corrections were made for the different recovery of the various volatiles, so the calculated concentrations were regarded as semiquantitative only.

\section{PV and TBARS}

Peroxide value was analyzed according to AOCS official method Cd 8-53 (AOCS, 1995a) and calculated in milliequivalents per kilogram of butter lipids. Thiobarbituric acid-reactive substances were analyzed according to AOCS official method Cd 19-90 (AOCS, 1995b) and given as milligrams of malondialdehyde per kilogram of lipid.

\section{Data Analyses}

Partial least squares (PLS) regression, with full cross-validation, was used to find the correlations among sensory analysis and fluorescence spectroscopy, dynamic headspace/GC-MS, PV, and TBARS. Partial least squares regression was performed with the software The Unscrambler (v. 9.2, Camo AS, Oslo, Norway). Full cross-validation was used to determine the optimal number of PLS factors. Student's $t$-tests were performed with Minitab (v. 14.20, Minitab Inc., State College, PA). To extract pure spectra and concentration profiles from the fluorescence data matrix, multivariate curve resolution (MCR) was carried out with Matlab (v. 7.0.4, MathWorks, Natick, MA) using the PLS Toolbox (v. 3.0, Eigenvector Research Inc., Manson, WA). A nonnegativity constraint was placed on both the concentration profiles and spectra. The algorithm for MCR has been described in detail by Tauler (1995) and Tauler et al. (1995).

\section{RESULTS AND DISCUSSION}

\section{Sensory Analysis}

The butter stored in air became very rancid during the storage period. At $\mathrm{d} 5$ and 7 , the rancid flavor and odor intensity were 9 , on a scale of 1 to 9 (where 9 is the highest intensity). The acidic flavor, which is a desirable attribute, decreased throughout the storage period. For the sunlight flavor and odor in the butter stored in air, an initial increase during the first $36 \mathrm{~h}$ was followed by a decrease. The decrease was probably due to a masking of the sunlight flavor by the more intense rancid flavor. This was apparent for samples with rancid flavor intensities higher that approximately 4.5. Figure 1 shows the development of the rancid flavor score for both storage conditions. As expected, the samples stored in $\mathrm{N}_{2}$ were more stable toward photooxidation; however, significant quality deterioration also occurred in these samples.

\section{Fluorescence Analysis}

Fluorescence emission spectra from butter stored in air and $\mathrm{N}_{2}$ are shown in Figures 2 and 3, respectively. The peaks at 535, 622, 635, 661, and $672 \mathrm{~nm}$ originated from riboflavin, hematoporphyrin, protoporphyrin, and 2 types of chlorophyll derivatives (Wold et al., 2005), respectively. The small peak at $705 \mathrm{~nm}$ was the second peak of protoporphyrin. These compounds are photosensitizers and potential initiators of photooxidation. During the storage period, photodegradation caused an overall decrease in the fluorescence intensity of these peaks. Riboflavin showed approximately the same decrease in samples stored in air and $\mathrm{N}_{2}$. The chlorophyll derivatives (especially the one at $672 \mathrm{~nm}$ ) degraded more in the $\mathrm{N}_{2}$-stored samples after $24 \mathrm{~h}$ of light exposure.

The fluorescence intensity in the 410 - to $500-\mathrm{nm}$ region increased for butter stored in air after light exposure for 5 and $7 \mathrm{~d}$. This emerging peak indicated the formation of fluorescent oxidation products. To accentuate this development, fluorescence was measured in butter exposed for $14 \mathrm{~d}$ (Figure 4). For butter stored in air, there was a large increase in fluorescence intensity, with the maximum around 465 to $470 \mathrm{~nm}$. For butter stored in $\mathrm{N}_{2}$, the formation of fluorescent oxidation products was not detected, although the butter had a rancid flavor intensity of 6.5 after $168 \mathrm{~h}$ of light exposure. The fluorescent lipid oxidation products in butter were detectable very late in the oxidation process compared with changes in the sensory attributes. This result was in contrast to poultry meat, in which the development of the corresponding fluorescence peak gives 


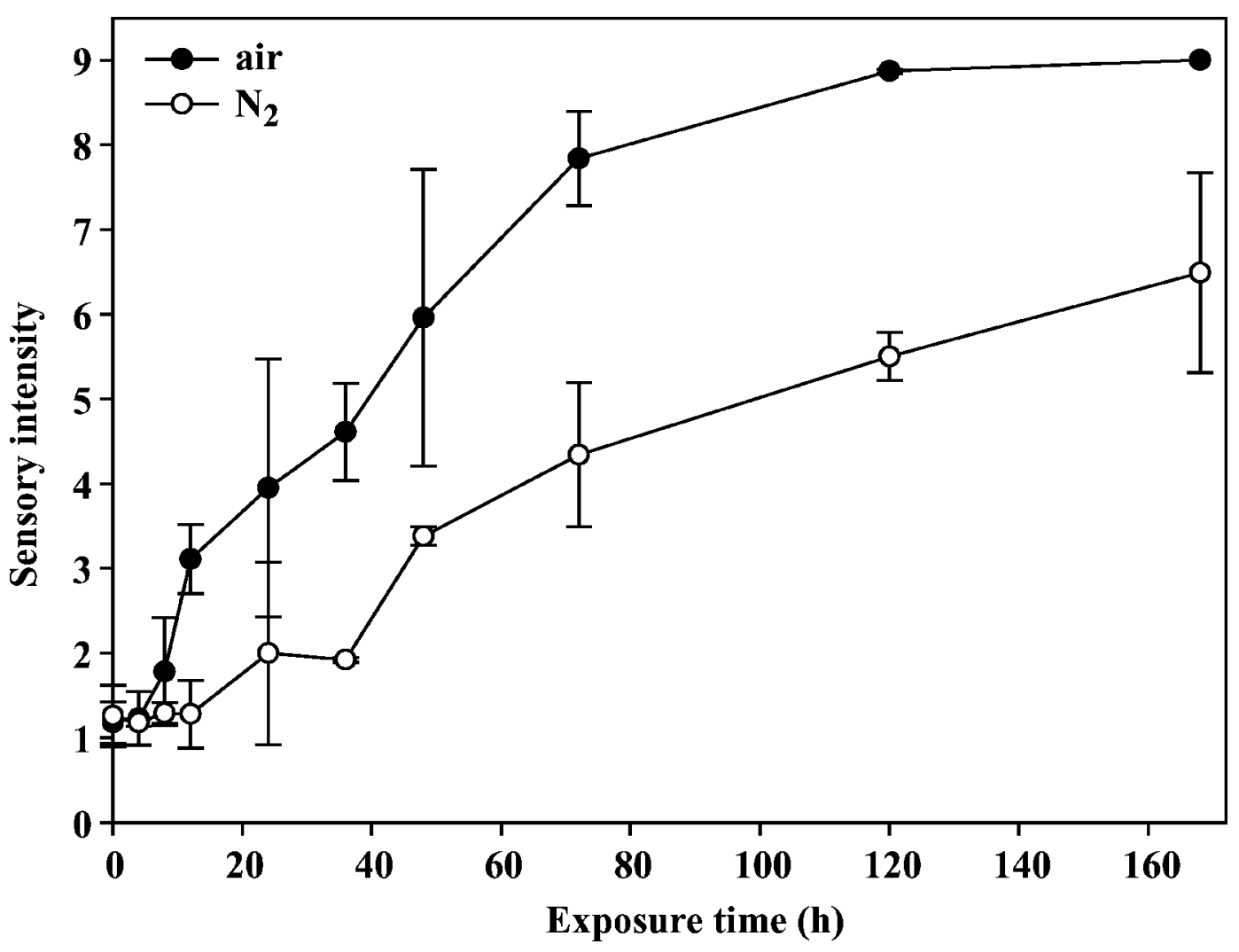

Figure 1. Development of rancid flavor intensity for light-exposed butter stored in air and $\mathrm{N}_{2}$. Standard deviations are shown as error bars.

an early indication of lipid oxidation and correlates well with sensory properties (Veberg et al., 2006a).

The pure spectrum of the oxidation products could be estimated by MCR of the fluorescence data in the region of 420 to $620 \mathrm{~nm}$. Figure 5 shows the estimated pure spectra of the lipid oxidation products. The lipid oxidation peak has a maximum at $470 \mathrm{~nm}$ and is similar to the one seen for lipid oxidation products in stored salted cod, turkey, chicken meat, and salmon pâté (Wold and Kvaal, 2000; Olsen et al., 2006; Veberg et al., 2006a,b). This suggests that quite different food matrices have a common lipid oxidation peak at around $470 \mathrm{~nm}$.

By MCR, we also estimated the relative concentrations of the fluorescent oxidation products in each sample (Figure 6). In the butter with access to air, the formation of lipid oxidation products increased notably after $72 \mathrm{~h}$ of light exposure. In contrast, no oxidation peaks were formed in the butter stored in $\mathrm{N}_{2}$. The unexplained variance in the MCR model was only $0.1 \%$, which indicated a good fit and a reliable model.

The 410- to 500-nm region contains several fluorophores. The peak at $470 \mathrm{~nm}$ can be formed by the reaction of aldehydes with proteins or AA (Yamaki et al., 1992; Veberg et al., 2006b). When riboflavin is exposed to light, it is also known to degrade photochemically into different forms of lumichrome and lumiflavin. These compounds have emission maxima around 462 and 521 nm, respectively (Fox and Thayer, 1998). Lumichrome might thereby have contributed to the oxidation peak around 465 to $470 \mathrm{~nm}$. A slight shift toward lower wavelengths was observed for the riboflavin peak during exposure, which might involve the formation of lumiflavin, as also observed by Karoui et al. (2007) during the ripening of cheese. Others (Miquel Becker et al., 2003; Christensen et al., 2005) have found a peak for yogurt at $430 \mathrm{~nm}$ (e.g., maximum $370 \mathrm{~nm}$ ) that increased during light exposure and could correspond to lumichrome.

\section{PV and TBARS}

The development of peroxides is shown in Figure 7. After light exposure in air and $\mathrm{N}_{2}$, the PV were 9.9 and $0.9 \mathrm{mEq} / \mathrm{kg}$, respectively. The PV for butter stored in air and $\mathrm{N}_{2}$ were different $(P<0.05)$ from those of the control sample (packed in $\mathrm{N}_{2}$ and stored in the dark) after $8 \mathrm{~h}$ and $5 \mathrm{~d}$ of exposure, respectively. The development of peroxides for the butter stored in air was close to linear, as also observed by Foley et al. (1971). 


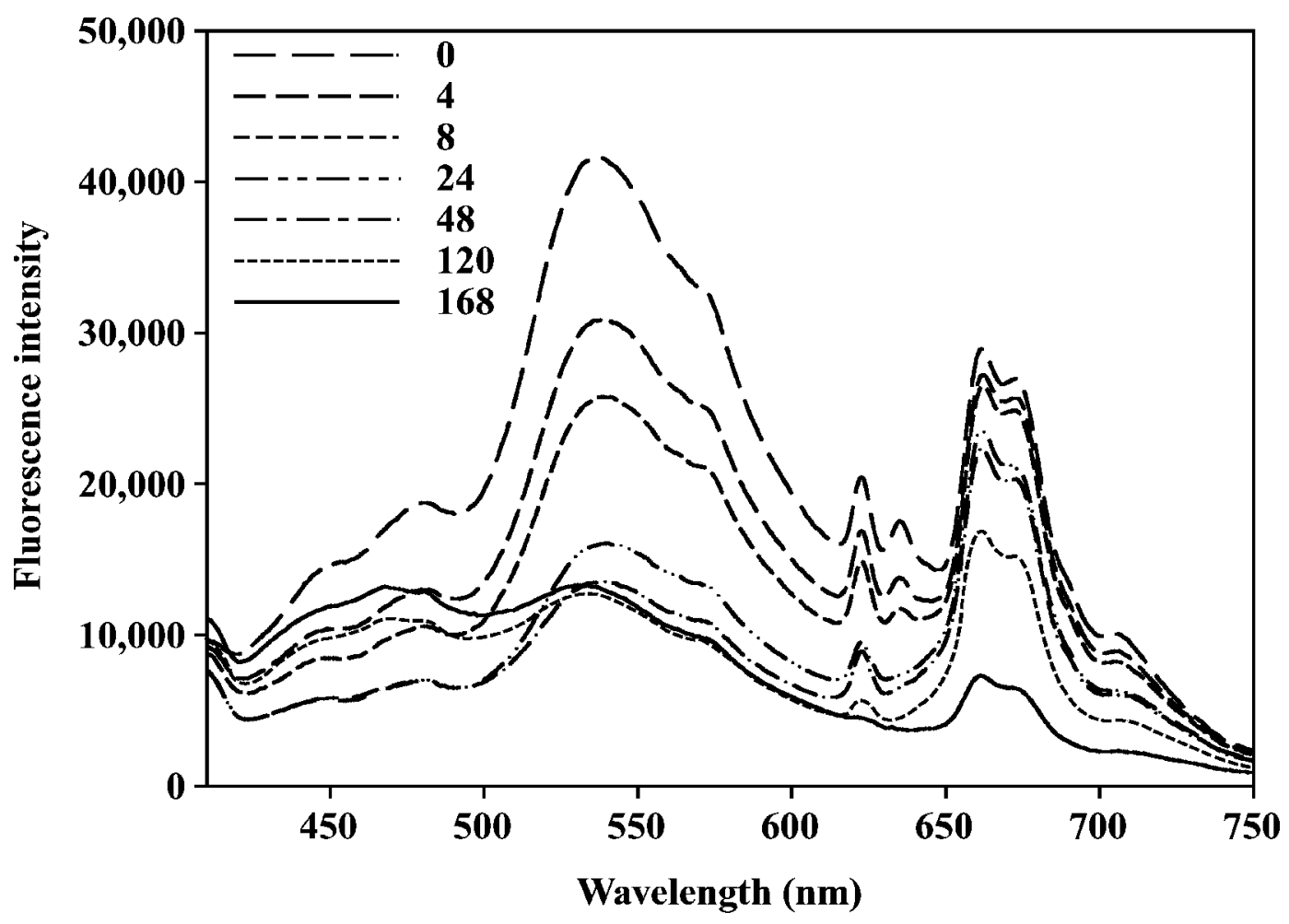

Figure 2. Fluorescence emission spectra of light-exposed butter stored in air at $3^{\circ} \mathrm{C}$.

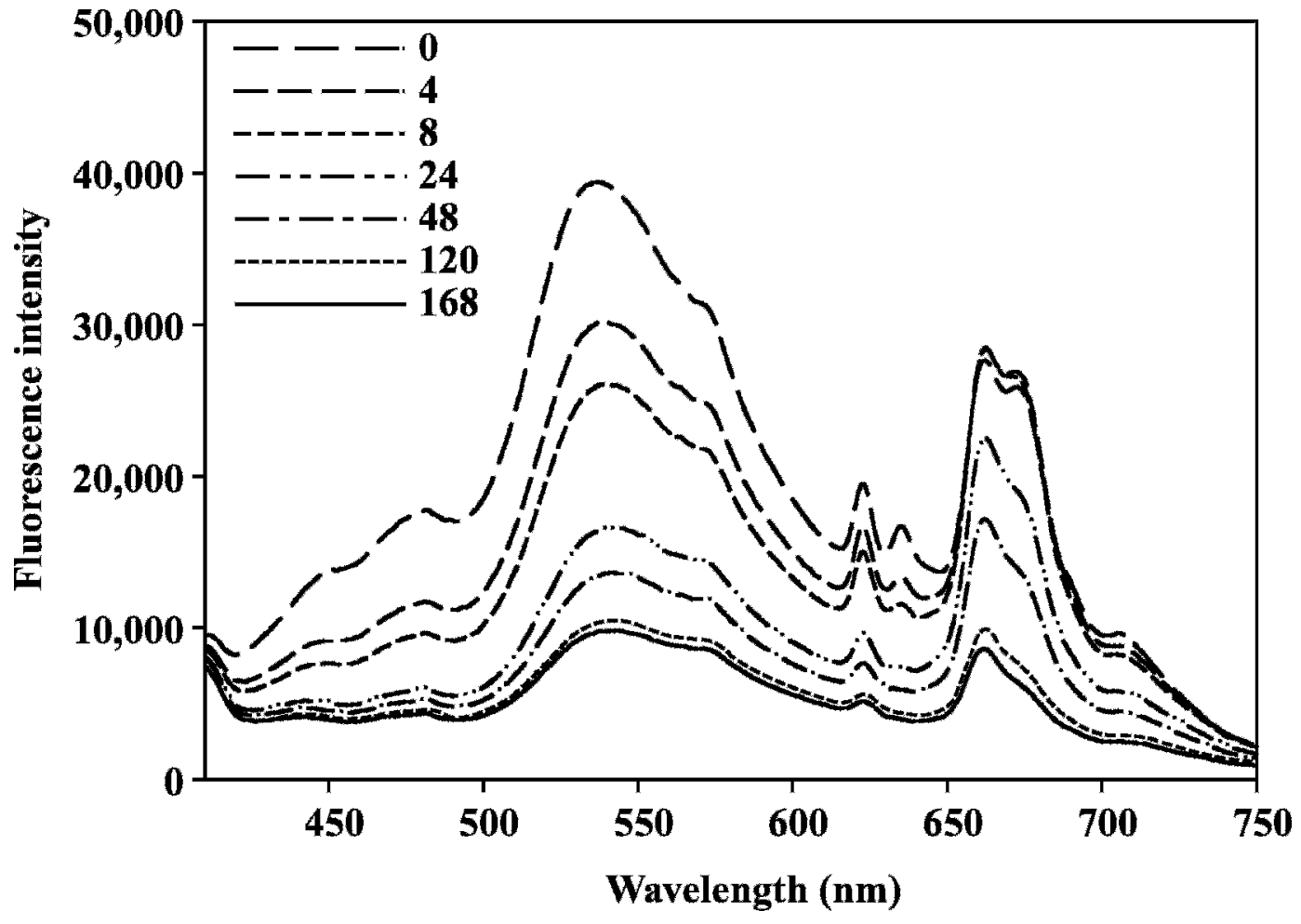

Figure 3. Fluorescence emission spectra of light-exposed butter stored in $\mathrm{N}_{2}$ at $3^{\circ} \mathrm{C}$. 


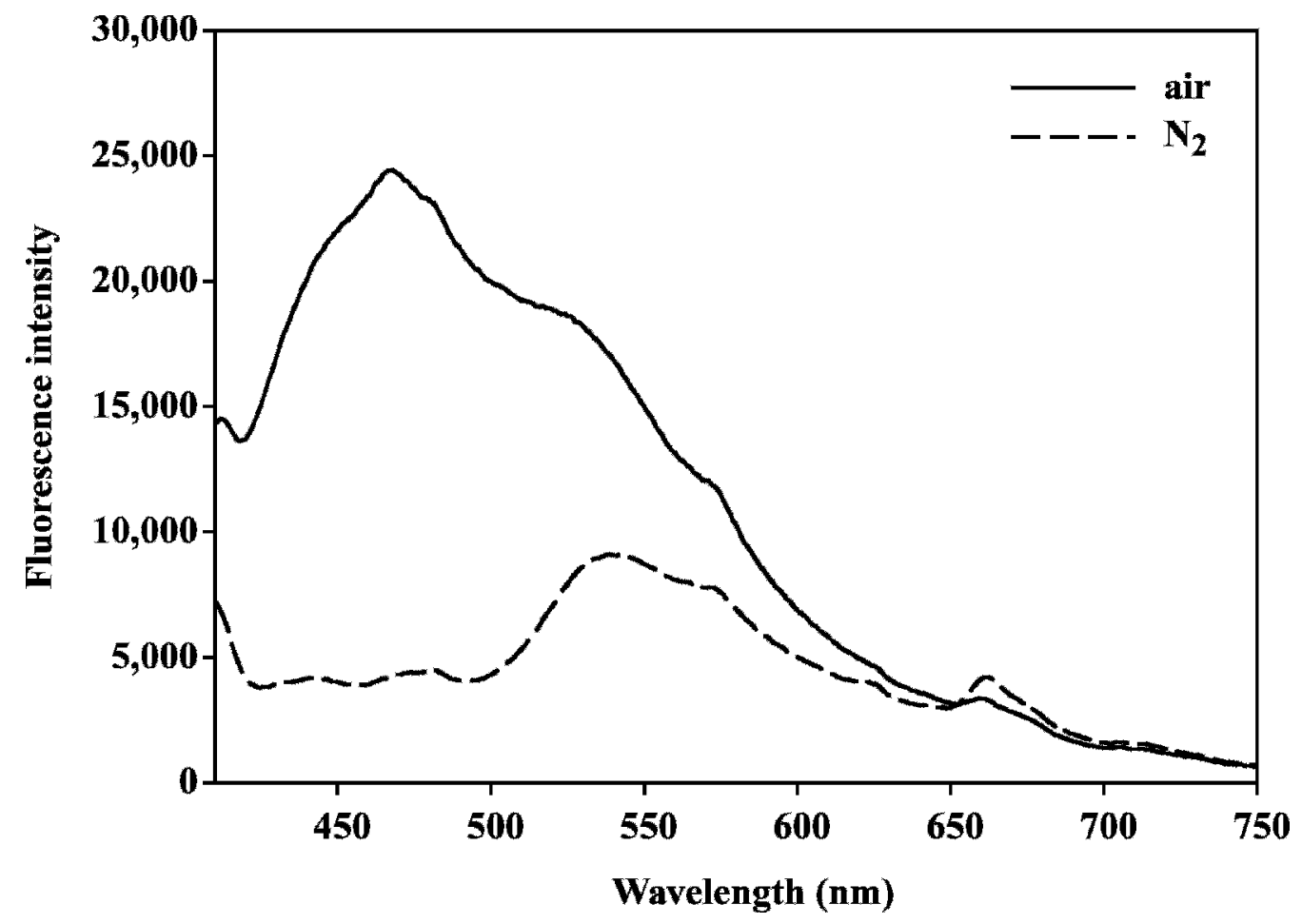

Figure 4. Fluorescence emission spectra of light-exposed butter for $14 \mathrm{~d}$, stored in air and $\mathrm{N}_{2}$.

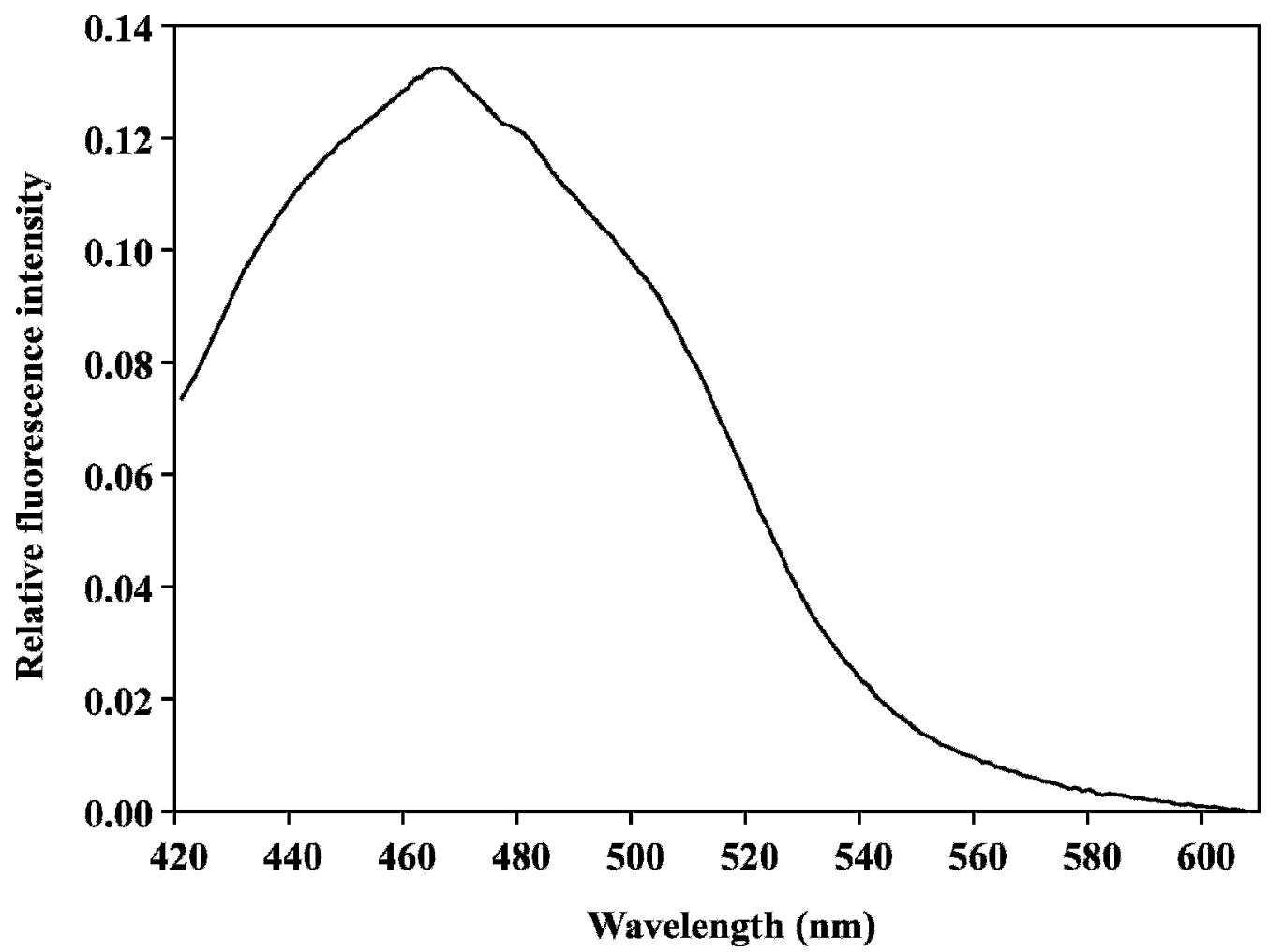

Figure 5. Estimated pure fluorescence emission spectrum of lipid oxidation products in light-exposed butter. 


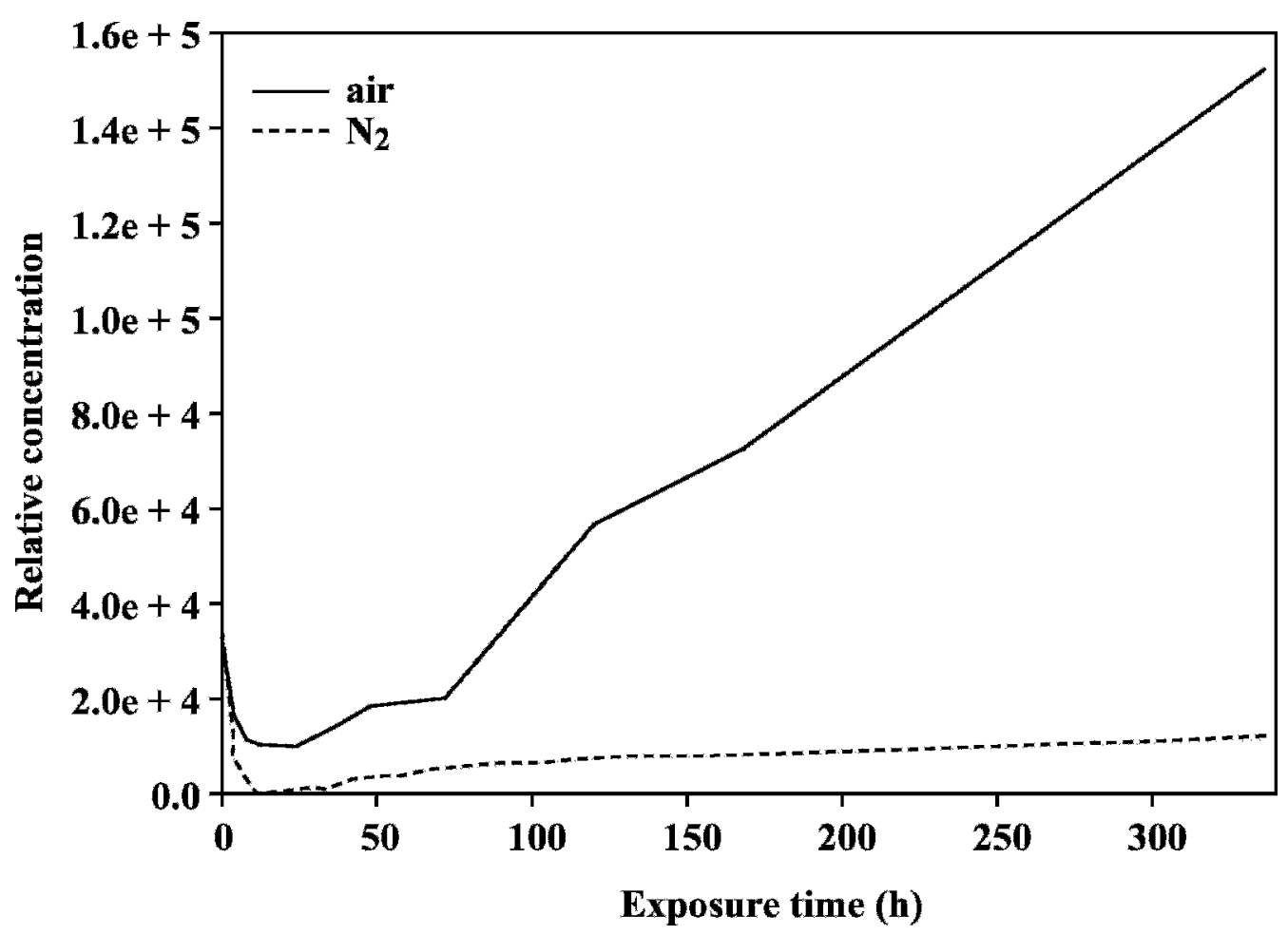

Figure 6. Relative concentrations of fluorescent lipid oxidation products during light exposure.

The TBARS method gave low TBARS values, and it was difficult to obtain good parallels. The samples stored with access to air showed nonsignificant increases in TBARS during the storage period and reached a value of $0.03 \mathrm{mg}$ of malondialdehyde/ $\mathrm{kg}$ of lipids after $168 \mathrm{~h}$ of light exposure. No changes were detected in the $\mathrm{N}_{2}$-stored samples during the experiment. These results indicate that the chosen TBARS method was not suitable for measuring photooxidation in butter. The fluorescence peak at $470 \mathrm{~nm}$ has previously been shown to be highly correlated with TBARS values for minced poultry meat and complex meat products (Wold et al., 2002b; Veberg et al., 2006a).

\section{Volatile Components}

The concentrations of pentanal, hexanal, and heptanal increased during storage in air. The pentanal peak contained 2-pentanone, but as assessed by the MS spectra, this compound was relatively stable with regard to the area of the peak. The increase in pentanal could thus mainly be ascribed to pentanal and not to 2-pentanone. The increasing concentration of aldehydes in the present experiment was directly related to the amount of oxygen available. Methional is often referred to as the compound that gives a sunlight flavor (Skibsted, 2000). Kim and Morr (1996) have found methional, hex- anal, pentanal, and dimethyldisulfide in the headspace of milk exposed to fluorescent light. The dynamic headspace/GC-MS method used in this experiment could not detect methional. However, methional may not be as important as once believed, and studies point toward dimethyldisulfide as a high-impact compound in photooxidized milk (Kim and Morr, 1996; Jung et al., 1998). Dimethyldisulfide was detected in the butter samples, but the concentration was much lower than for the aldehydes mentioned above. The levels of 2-butanone and 2,3-butanedione were somewhat higher in samples stored in $\mathrm{N}_{2}$ than in those exposed to air. The level of 2,3-butanedione in the $\mathrm{N}_{2}$ sample was significantly different $(P<0.05)$ from the sample in air after $7 \mathrm{~d}$ of light exposure.

\section{Correlations}

To investigate how well the fluorescence spectra, PV, pentanal, and hexanal correlated with sensory assessments of acidic and rancid flavors, a PLS regression was performed. The results are shown in Table 1. Fluorescence correlated well with both acidic and rancid flavors, and the explained variance was 93 and $95 \%$, respectively. Pentanal also correlated fairly well with the rancid flavor. 


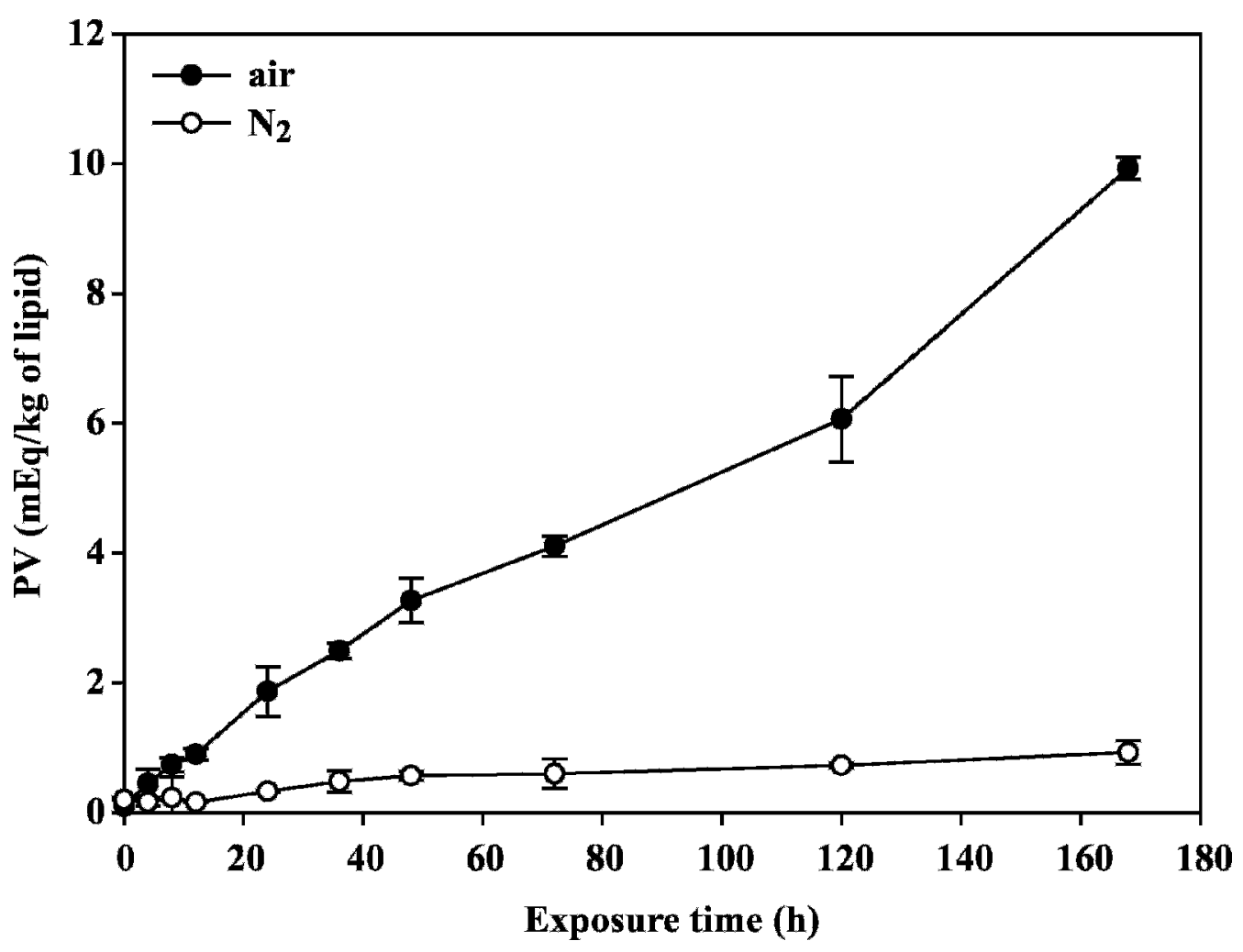

Figure 7. Development of peroxide value (PV) for light-exposed butter stored in air and $\mathrm{N}_{2}$. Standard deviations are shown as error bars.

\section{Effect of Adding $\beta$-Carotene}

The effect of adding the ${ }^{1} \mathrm{O}_{2}$ quencher $\beta$-carotene to butter before light exposure is shown in Figure 8. Addition of $\beta$-carotene reduced the rancid flavor intensity for the samples stored in air as well as in $\mathrm{N}_{2}$; however, the inhibitory effect was much larger in the air-stored samples. This was as expected because part of the photooxidation taking place in the $\mathrm{N}_{2}$ packages was probably caused by direct photooxidation and by type II photosensitization. The fluorescence spectra showed the same trend as for butter without $\beta$-carotene.

\section{Reaction Mechanisms}

The results indicated that the high level of oxidation in the air-stored butter was caused by formation of ${ }^{1} \mathrm{O}_{2}$. It is likely that direct photooxidation as well as type II photosensitized photooxidation occurred in the butter samples because they were exposed to UV light. Both reactions will produce the highly reactive ${ }^{1} \mathrm{O}_{2}$ during light exposure. In a given system, both type I and type II reactions can take place simultaneously in a competitive fashion (Spikes, 1989). Low $\mathrm{O}_{2}$ availability, as in the $\mathrm{N}_{2}$ packages, would favor the photosensitized reaction toward the type I mechanism, and high $\mathrm{O}_{2}$ avail- ability would favor the type II reactions. Type I reactions are complex. Free radicals are produced that can give different hydroperoxides as well as other products such as alcohols, epoxides, and ketones. The type II reactions are simpler and mainly yield hydroperoxides, with only traces of other products (Spikes, 1989). The higher concentrations of 2-butanone and 2,3-butandione in the $\mathrm{N}_{2}$-stored butter suggested that the main reaction mechanisms in these samples were type I.

The higher degradation of chlorophyll derivatives in the $\mathrm{N}_{2}$-stored samples might indicate that in the type I reactions, the energy from the light preferentially degraded the photosensitizers, whereas with the type II reactions taking place in the air-stored samples, the light energy mainly contributed to degradation of unsaturated fatty acids. The packages with $\mathrm{N}_{2}$ contained traces of $\mathrm{O}_{2}$, so some ${ }^{1} \mathrm{O}_{2}$ was probably also produced in these samples, and addition of the ${ }^{1} \mathrm{O}_{2}$ quencher $\beta$ carotene had an effect on the level of oxidation.

In living cells, the photooxidation of porphyrins depends on the oxygen level present. High oxygen concentrations will degrade the porphyrins more efficiently than low oxygen concentrations (Moan and Sommer, 1985). The opposite was observed in this experiment. Low oxygen concentrations resulted in more degradation of protoporphyrin and the chlorophyll derivatives 
Table 1. Results from partial least squares (PLS) regression for fluorescence, peroxide value, pentanal, and hexanal against sensory-assessed acidic and rancid flavors ${ }^{1}$

\begin{tabular}{lccccccc}
\hline & \multicolumn{3}{c}{ Acidic flavor } & & \multicolumn{3}{c}{ Rancid flavor } \\
\cline { 2 - 5 } \cline { 5 - 7 } Item & $\mathrm{R}$ & $\mathrm{H}$ & $\begin{array}{c}\text { RMSECV } \\
(\%)\end{array}$ & & $\mathrm{R}$ & \#F & $\begin{array}{c}\text { RMSECV } \\
(\%)\end{array}$ \\
\hline Fluorescence & 0.97 & 4 & 7.3 & 0.96 & 4 & 9.2 \\
Peroxide value & 0.61 & 1 & 28.1 & 0.73 & 1 & 25.3 \\
Pentanal & 0.76 & 1 & 20.9 & & 0.86 & 1 & 16.9 \\
Hexanal & 0.61 & 1 & 30.5 & & 0.72 & 1 & 28.9 \\
\hline
\end{tabular}

${ }^{1} \mathrm{n}=20$. $\mathrm{R}$ gives the correlation coefficient; \#F gives the number of PLS regression factors used in the model; RMSCV is the root mean square error of cross-validation.

(especially the one at $672 \mathrm{~nm}$ ). This discrepancy could not be explained.

\section{CONCLUSIONS}

This study shows the simultaneous measurement of the degradation of photosensitizers and the formation of lipid oxidation products in light-exposed butter by fluorescence spectroscopy. The degradation of photosensitizers was detected at a very early stage of the experiment, indicating the initiation of lipid oxidation. In contrast, increasing levels of fluorescent lipid oxidation products were observed at prolonged storage. The fluorescence measurements were highly correlated with sensory assessments of acidic and rancid flavors, and measurements of the degradation of photosensitizers are therefore a valuable tool for rapidly monitoring the lipid oxidation in butter indirectly.

The high level of lipid oxidation in the butter samples stored in air was probably caused by ${ }^{1} \mathrm{O}_{2}$ produced by

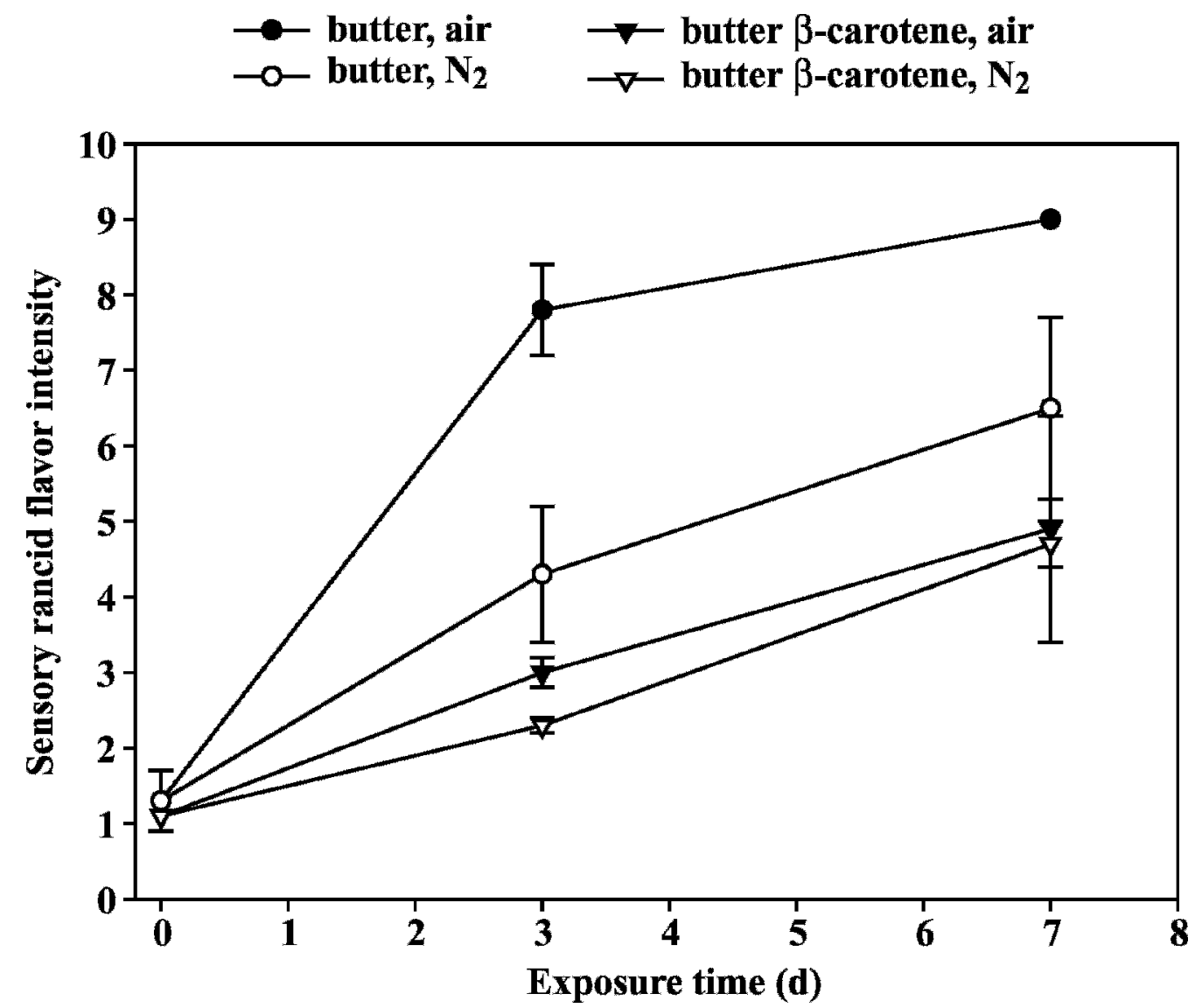

Figure 8. Rancid flavor intensity for light-exposed butter with and without $\beta$-carotene. Standard deviations are shown as error bars. 
both direct photooxidation and photosensitized oxidation of type II. In the butter stored in $\mathrm{N}_{2}$, the lipid oxidation was probably mainly caused by a type I photosensitized reaction, because addition of $\beta$-carotene had little effect on the rancid flavor intensity.

\section{ACKNOWLEDGMENTS}

The authors thank Aud Espedal, Karin Solgaard, and Inger-Johanne Fjøsne at the Norwegian Food Research Institute for excellent technical assistance. We also thank Johan Moan at the Norwegian Radium Hospital for fruitful discussions. The Research Council of Norway is greatly appreciated for funding this research (NFR-147204/130).

\section{REFERENCES}

AOCS (American Oil Chemists' Society). 1995a. Method Cd 8-53. Official Methods and Recommended Practices of the American Oil Chemists' Society. D. Firestone, ed. AOCS Press, Champaign, IL.

AOCS (American Oil Chemists' Society). 1995b. Method Cd 19-90. Official Methods and Recommended Practices of the American Oil Chemists' Society. D. Firestone, ed. AOCS Press, Champaign, IL.

Bosset, J. O., P. U. Gallmann, and R. Sieber. 1994. Influence of light transmittance of packaging materials on the shelf-life of milk and dairy products-A review. Pages 223-268 in Food Packaging and Preservation. M. Mathlouthi, ed. Blackie, London, UK.

Bosset, J. O., R. Sieber, and P. U. Gallmann. 1995. Light transmittance: Influence on the shelf life of milk and milk products. Pages 19-39 in Technical Guide for the Packaging of Milk and Milk Products. 3rd ed. International Dairy Federation, ed. International Dairy Federation, Brussels, Belgium.

Christensen, J., E. M. Becker, and C. S. Frederiksen. 2005. Fluorescence spectroscopy and PARAFAC in the analysis of yogurt. Chemometr. Intel. Lab. 75:201-208.

Foley, J., D. O'Donovan, and C. Cooney. 1971. Photo-catalysed oxidation of butter. J. Soc. Dairy Technol. 24:38-45.

Fox, J. B., and D. W. Thayer. 1998. Radical oxidation of riboflavin. Int. J. Vitam. Nutr. Res. 68:174-180.

Frankel, E. N. 2005. Lipid Oxidation. 2nd ed. The Oily Press, Davis, CA.

Hansen, E., and L. H. Skibsted. 2000. Light-induced oxidative changes in a model dairy spread. Wavelength dependence of quantum yields. J. Agric. Food Chem. 48:3090-3094.

He, Y. Y., J. Y. An, and L. J. Jiang. 1998. EPR and spectrophotometric studies on free radicals $\left(\mathrm{O}_{2}{ }^{--}\right.$, Cysa-HB'- $)$and singlet oxygen $\left({ }^{1} \mathrm{O}_{2}\right)$ generated by irradiation of cysteamine substituted hypocrellin B. Int. J. Radiat. Biol. 74:647-654.

ISO (International Organization for Standardization). 1993. International Standard 8586. Sensory Analysis Methodology-General Guidance for the Selection, Training, and Monitoring of Assessors. Part 1: Selected Assessors. 1st ed. ISO, Geneva, Switzerland.

Jung, M. Y., S. H. Yoon, H. O. Lee, and D. B. Min. 1998. Singlet oxygen and ascorbic acid effects on dimethyl disulfide and offflavor in skim milk exposed to light. J. Food Sci. 63:408-412.
Karoui, R., E. Dufour, and J. De Baerdemaeker. 2007. Front face fluorescence spectroscopy coupled with chemometric tools for monitoring the oxidation of semi-hard cheeses throughout ripening. Food Chem. 101:314-323.

Kim, Y. D., and C. V. Morr. 1996. Dynamic headspace analysis of light activated flavor in milk. Int. Dairy J. 6:185-193.

Lawless, H. T., and H. Heymann. 1998. Sensory Evaluation of Food: Principles and Practices. Chapman \& Hall, New York, NY.

Miquel Becker, E., J. Christensen, C. S. Frederiksen, and V. K. Haugaard. 2003. Front-face fluorescence spectroscopy and chemometrics in analysis of yogurt: Rapid analysis of riboflavin. J. Dairy Sci. 86:2508-2515.

Moan, J., and S. Sommer. 1985. Oxygen dependence of the photosensitizing effect of hematoporphyrin derivative in NHIK 3025 cells. Cancer Res. 45:1608-1610.

Olsen, E., A. Veberg, G. Vogt, O. Tomic, B. Kirkhus, D. Ekeberg, and A. Nilsson. 2006. Analysis of early lipid oxidation in salmon pâté with cod liver oil and antioxidants. J. Agric. Food Chem. 71:284-292.

Olsen, E., G. Vogt, K. Saarem, T. Greibrokk, and A. Nilsson. 2005. Autoxidation of cod liver oil with tocopherol and ascorbyl palmitate. J. Am. Oil Chem. Soc. 82:97-103.

Skibsted, L. H. 2000. Light-induced changes in dairy products. Bull. Int. Dairy Found. 346:4-9.

Spikes, J. D. 1989. Photosensitization. Pages $79-110$ in The Science of Photobiology. 2nd ed. K. C. Smith, ed. Plenum Press, New York, NY.

Stratton, S. P., and D. C. Liebler. 1997. Determination of singlet oxygen-specific versus radical-mediated lipid peroxidation in photosensitized oxidation of lipid bilayers: Effect of $\beta$-carotene and $\alpha$-tocopherol. Biochemistry 36:12911-12920.

Tauler, R. 1995. Multivariate curve resolution applied to second order data. Chem. Intel. Lab. Sys. 30:133-146.

Tauler, R., A. Smilde, and B. Kowalski. 1995. Selectivity, local rank, 3 -way data-analysis and ambiguity in multivariate curve resolution. J. Chemometr. 9:31-58.

Veberg, A., E. Olsen, G. Vogt, M. Mielnik, A. N. Nilsen, and J. P. Wold. 2006a. Front face fluorescence spectroscopy-A rapid method to detect early lipid oxidation in freeze stored minced turkey meat. J. Food Sci. 71:S364-S370.

Veberg, A., G. Vogt, and J. P. Wold. 2006b. Fluorescence in aldehyde model systems related to lipid oxidation. LWT-Food Sci. Technol. 39:562-570.

Wold, J. P., K. Jørgensen, and F. Lundby. 2002a. Nondestructive measurement of light-induced oxidation in dairy products by fluorescence spectroscopy and imaging. J. Dairy Sci. 85:1693-1704.

Wold, J. P., and K. Kvaal. 2000. Mapping lipid oxidation in chicken meat by multispectral imaging of autofluorescence. Appl. Spectrosc. 54:900-909.

Wold, J. P., M. Mielnik, M. K. Pettersen, K. Aaby, and P. Baardseth. $2002 \mathrm{~b}$. Rapid assessment of rancidity in complex meat products by front face fluorescence spectroscopy. J. Food Sci. 67:2397-2404.

Wold, J. P., A. Veberg, A. Nilsen, V. Iani, P. Juzenas, and J. Moan. 2005 . The role of naturally occurring chlorophyll and porphyrins in light-induced oxidation of dairy products. A study based on fluorescence spectroscopy and sensory analysis. Int. Dairy J. 15:343-353.

Yamaki, S., T. Kato, and K. Kikugawa. 1992. Characteristics of fluorescence formed by the reaction of proteins with unsaturated aldehydes. Possible degradation products of lipid radicals. Chem. Pharm. Bull. 40:2138-2142. 